\title{
MURPHY-BROOKFIELD BOOKS
}

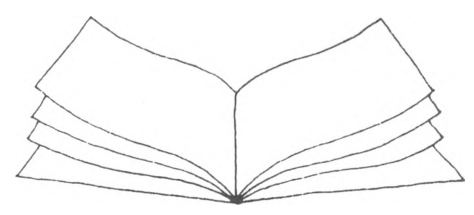

219 N. Gilbert

Iowa City, IA 52240

(319) 338-3077

Mon-Sat 11-6

\section{GENERAL \& SCHOLARLY USED BOOKS}

\section{The Center for Credit Programs}

\section{College credit at your convenience from The University of lowa}

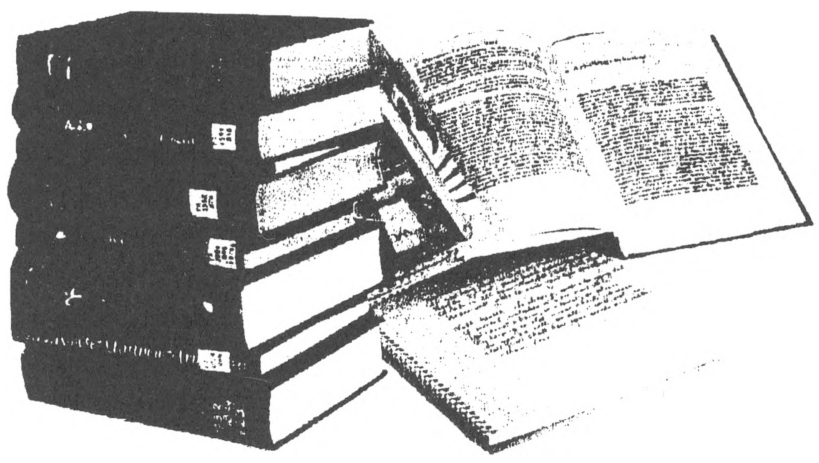

For more information call 335-2575 or write to the Center for Credit Programs, Division of Continuing Education, 116 International Center, The University of lowa, lowa City, lowa 52242. 

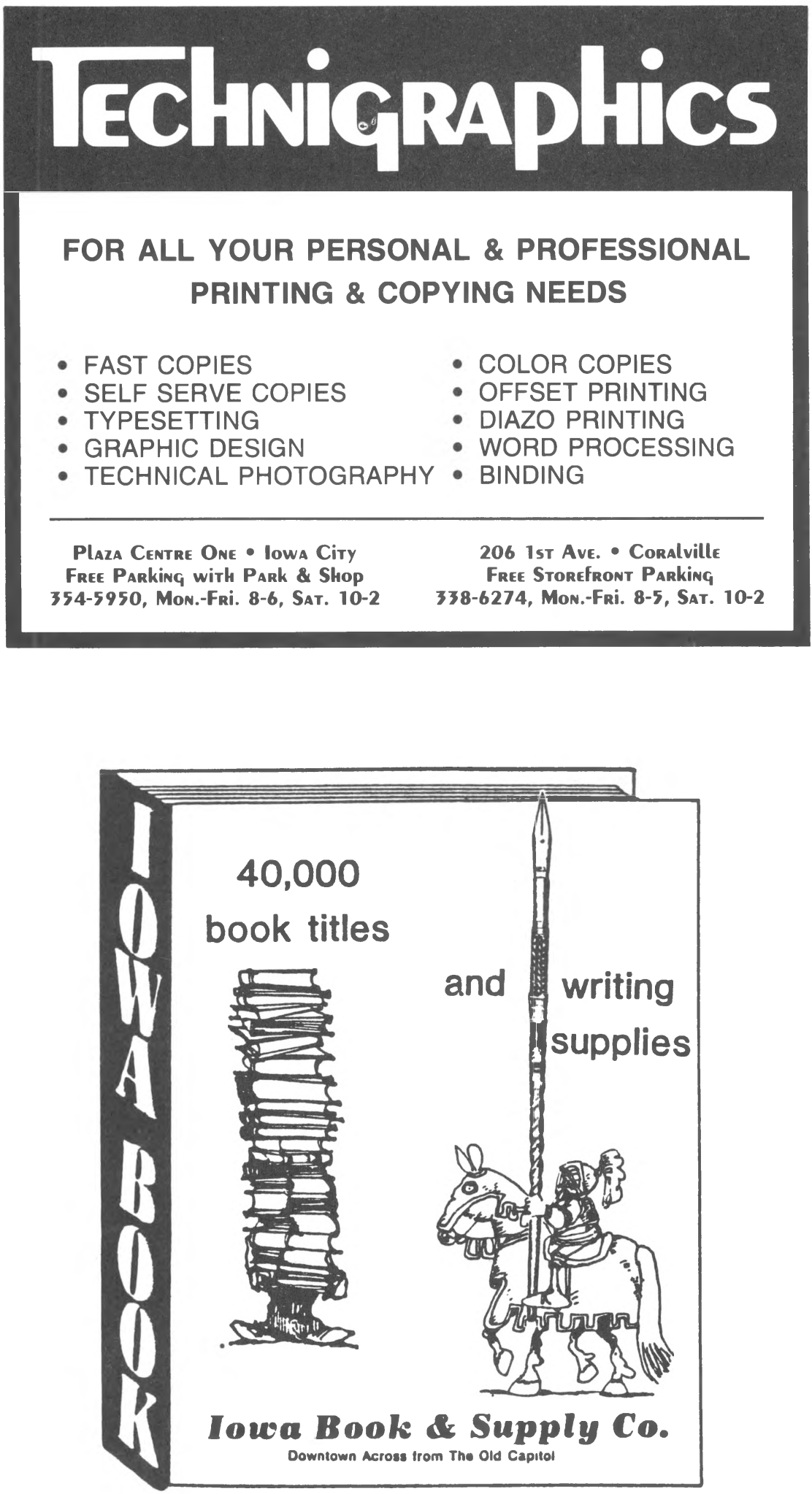


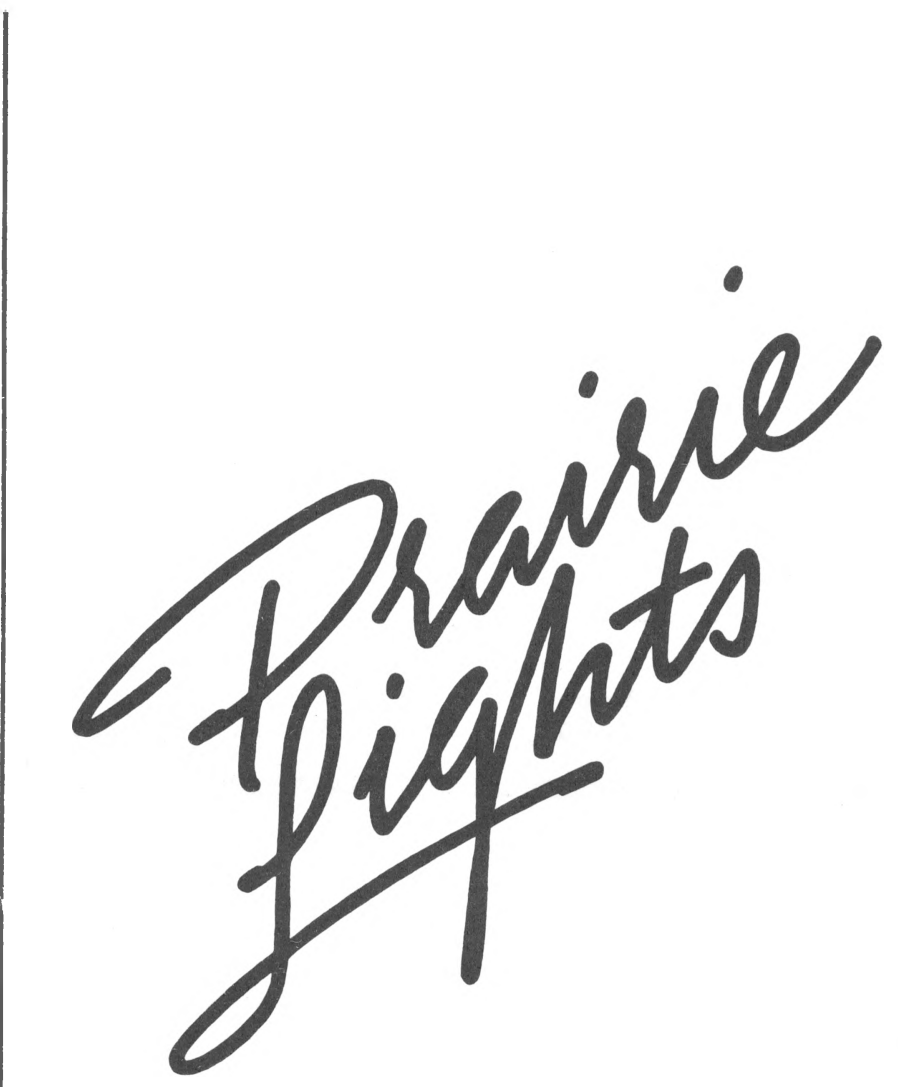

15 South Dubuque St. Iowa City - USA 319/337-2681 


\section{Supplies for the imagination"}

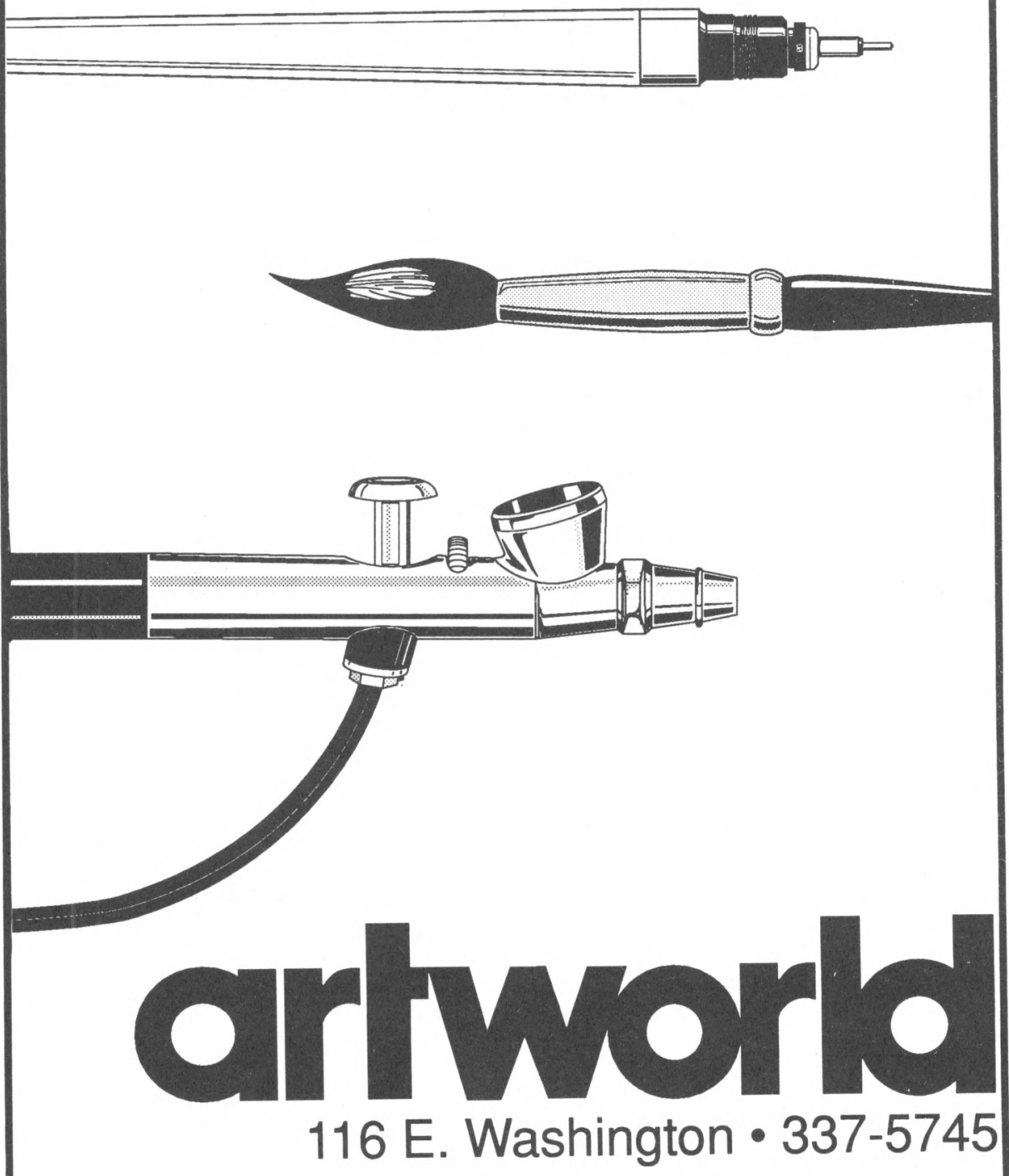




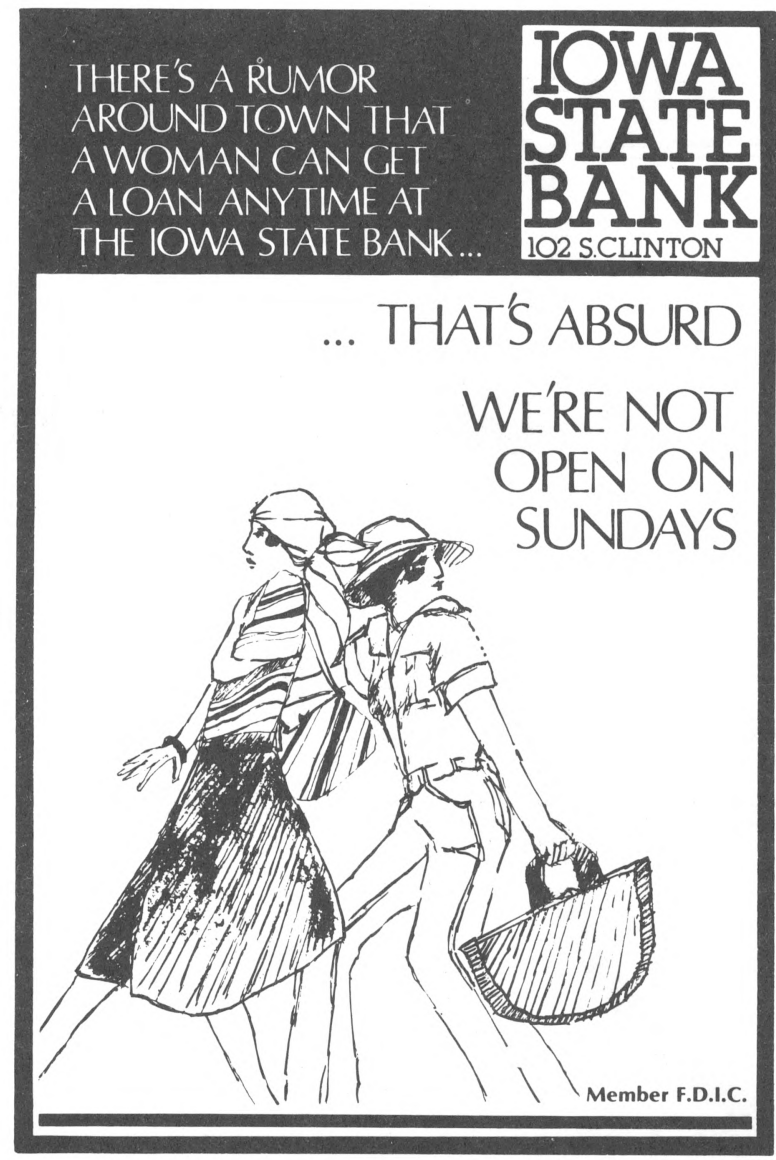




\section{ZEPHYR COPIES}

High-speed duplicating

Soft binding

Passport photos

Seven machines available for customer use

\section{ZEPHYR PLUS!}

Complete, affordable publishing services:

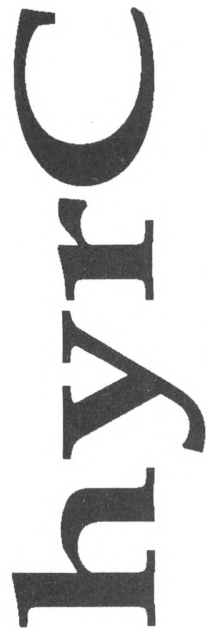
laser typesetting, design, printing, binding

- Books/manuscripts

- Theses

- Brochures/flyers

- One-Day Resumé Service and more...

Mailing list management

Laser prints from customer's (Macintosh) disks

\section{ZEPHYR SERVICE}

High Quality

Quick Turnaround

Reasonable Prices

Friendly Service

Open 7 Days a Week

124 E. Washington • (319) 351-3500 


\section{Well-read.}

The University Book Store now offers an expanded selection of books to tempt your literary palate! In addition to our wide assortment of publications ranging from new and used textbooks to time-honored classics, we now carry an increased volume of new titles, poetry, literary critiques, philosophy, and film books. The top five works on the New York Times bestseller list are regularly featured at at a $25 \%$ discount.

The Book Store also carries The American Poetry Review and The New York Times Book Review. Student ID's, MasterCard and Visa are welcome.

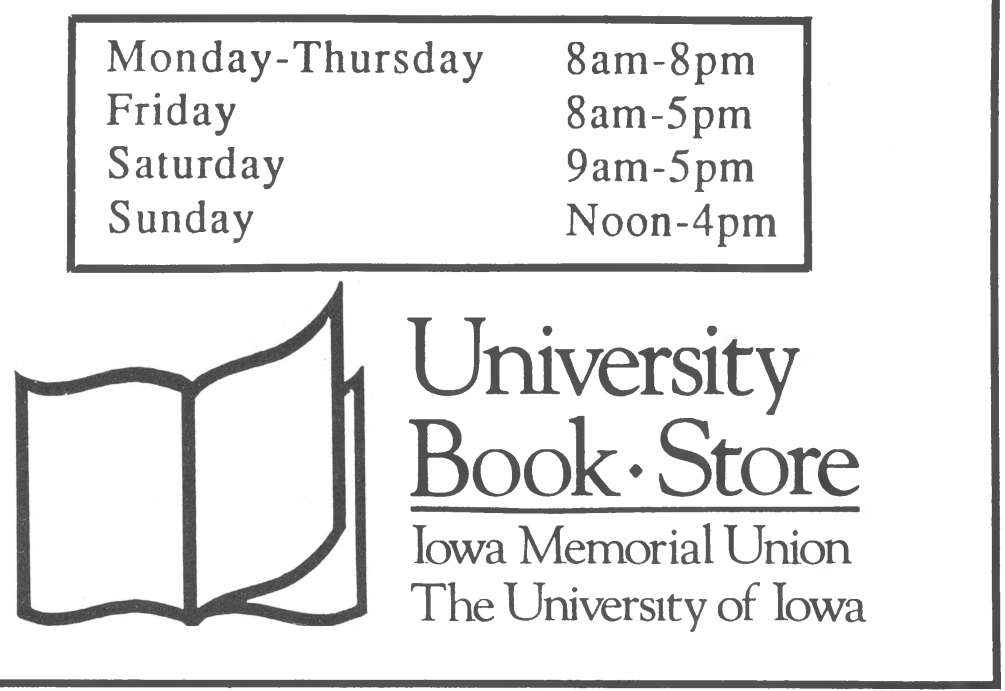

